1 Fundação Oswaldo Cruz (Fiocruz), Centro de Estudos Estratégicos (CEE)

- Rio de Janeiro (RJ), Brasil. Orcid: https://orcid. org/0000-0002-76787642

profsoniafleury@gmail.com

\section{Capitalismo, democracia, cidadania - contradições e insurgências}

\author{
Capitalism, democracy, citizenship - contradictions and insurgencies
}

Sonia Fleury ${ }^{1}$

DOI: $10.1590 / 0103-110420185309$

RESUMO O objetivo deste ensaio foi discorrer sobre as relações entre capitalismo, democracia e cidadania, tendo como foco as transformações recentes em todos os componentes da tríade Estadonacional, mercado capitalista e cidadania, que caracterizaram a construção da modernidade ocidental e geraram a democracia de massas, o Welfare State - ou Estado de Bem-Estar Social - e o mercado regulado. A globalização da economia levou à desterritorialização da produção e circulação de mercadorias e de capitais, em uma fase de predomínio da lógica de acumulação financeira, dissociando o mercado da dimensão nacional, sob a qual se exerce o poder político estatal. É preciso entender, no entanto, que as tensões entre capitalismo e democracia, e mesmo entre democracia e cidadania, são constitutivas dessa relação, nem sempre sendo contradições antagônicas, pois, em conjunturas específicas, diante das lutas socias e do acúmulo de forças em certas fases do processo de acumulação, pôde-se construir uma nova correlação de forças e viabilizar propostas contra-hegemônicas. A etapa atual deve ser compreendida como parte do acirramento dessas contradições, não como uma situação implacavelmente estagnada. A proposta é pensar, nesta conjuntura, o lugar da democracia e da cidadania.

PALAVRAS-CHAVE Democracia. Participação da comunidade. Capitalismo. Insurgências.

\begin{abstract}
The aim of this essay was to discuss the relations between capitalism, democracy and citizenship, focusing on the recent transformations in all components of the triad National-State, capitalist market and citizenship, which characterized the construction of Western modernity and generated mass democracy, Welfare State, and regulated market. The globalization of the economy led to the deterritorialization of the production and circulation of goods and capital, in a phase of predominance of the logic of financial accumulation, dissociating the market from the national dimension, under which the political power of the state is exerted. It must be understood, however, that the tensions between capitalism and democracy, and even between democracy and citizenship, are constitutive of such relation, not always being antagonistic contradictions, because, in specific conjunctures, in the face of social struggles and the accumulation of forces in certain phases of the process of accumulation, it was possible to build a new correlation of forces and to achieve viable anti-hegemonic proposals. The current stage must be understood as part of the aggravation of these contradictions, not as a relentlessly stagnant situation. The proposal is to think, in this juncture, about place of democracy and citizenship.
\end{abstract}

KEYWORDS Democracy. Community participation. Capitalism. Insurgences. 


\section{Introdução}

O objetivo deste ensaio é discorrer sobre as relações entre capitalismo, democracia e cidadania, tendo como foco as transformações recentes em todos os componentes da tríade Estado-nacional, mercado capitalista e cidadania, que caracterizaram a construção da modernidade ocidental e geraram a democracia de massas, o Welfare State (WS) - ou Estado de Bem-Estar Social - e o mercado regulado. A globalização da economia levou à desterritorialização da produção e circulação de mercadorias e de capitais, em uma fase de predomínio da lógica de acumulação financeira, dissociando o mercado da dimensão nacional, sob a qual se exerce o poder político estatal. A ausência de regulação da movimentação internacional do capital financeiro e o poder concentrado das grandes corporações transnacionais reduziram $\mathrm{O}$ poder de taxação e controle dos Estados, transformados em grandes devedores, o que limita a legitimidade dos governos, incapazes de responder às demandas cidadãs e garantir os direitos de proteção social.

As consequências dessas transformações são apontadas como produzindo severas restrições nas bases de sustentação do modelo social democrata que possibilitou a incorporação das lutas pela expansão da cidadania e pela redistribuição da riqueza produzida. Ao contrário, predomina a ideologia neoliberal, cujos valores do individualismo e da meritocracia não têm sido capazes de evitar o esgarçamento da coesão social e a emergência de articulação das insatisfações populares por líderes, de direita ou de esquerda, que tentam responder, dessa forma, ao aumento das desigualdades, do desemprego, da exclusão social e às ameaças de redução dos sistemas de proteção social.

O processo de desdemocratização ocorre, seja em democracias eleitorais consolidadas, seja em democracias emergentes, cujos projetos de inclusão social se tornam insustentáveis, ante a restrição do político, como reino da liberdade da ação coletiva na transação de conflitos sob normas aceitas. Impõe-se um regime de verdade no qual imperam os interesses do mercado, sem espaço para que os Estados cumpram uma função de capitalista geral, capaz de preservar a hegemonia com a concessão de medidas redistributivas, deslocando assim o conflito produtivo.

É preciso entender, no entanto, que as tensões entre capitalismo e democracia, e mesmo entre democracia e cidadania, são constitutivas dessa relação, nem sempre sendo contradições antagônicas, pois, em conjunturas específicas, diante das lutas socias e do acúmulo de forças em certas fases do processo de acumulação, pôde-se construir uma nova correlação de forças e viabilizar propostas contra-hegemônicas, como o próprio Estado Social. A etapa atual deve ser compreendida como parte do acirramento dessas contradições, não como uma situação implacavelmente estagnada.

Este trabalho não é uma resenha no sentido tradicional, mas um olhar dirigido sobre a bibliografia atual, em campos como economia, política, filosofia, com vistas a identificar fundamentos neste debate que nos permitam defender algumas ideias acerca das transformações na relação entre capitalismo, democracia e cidadania:

a) Essa relação, ainda que seja determinada pela dinâmica da acumulação capitalista, não pode ser limitada a ela, caindo assim no fetiche da razão econômica, pois as características do desenvolvimento da democracia e da cidadania têm uma dinâmica própria, que interage com a economia, influenciando-a. O resgate do político é parte de um contramovimento de preservação da possibilidade de coesão social e depende da ação política e da institucionalidade existentes em cada sociedade.

b) A complexificação da sociedade gerou uma polifonia de sujeitos e de novas formas de ação política, cada vez mais distanciados 
da representação e dos partidos tradicionais, reivindicando inovações democráticas que comportem a participação, a comunicação e a deliberação, que sejam capazes de contemplar assim as demandas dos movimentos sociais.

c) Esses novos sujeitos rompem a divisão liberal entre o cidadão como dimensão pública e o indivíduo como dimensão privada, introduzindo questões anteriormente consideradas privadas no debate sobre justiça e direitos sociais. A construção da proteção social é parte intrínseca da arquitetura democrática e deverá contemplar novas cidadanias e estratégias de inclusão, para além da homogeneidade, capazes de incorporar a diversidade sem abrir mão da igualdade, em cidadanias diferenciadas.

d) A questão social a ser enfrentada diz respeito tanto à desigualdade quanto à exclusão, que são fenômenos distintos e requerem abordagens próprias. As lutas contra a desigualdade se situam dentro do universo do Estado de Direito, onde direito igualitário não se realiza plenamente. $\mathrm{O}$ componente normativo da exclusão parte de diferenças injustamente utilizadas e reforça a dimensão socioeconômica, legitimando-a socialmente. Na exclusão, a violência e a substituição do Estado de Direito pelo Estado de Exceção - do WF pelo Warfare State - são naturalizadas e banalizadas no tratamento de populações e territórios considerados à margem da comunidade de direitos. Porém, a desobediência, a transgressão e a insurgência são componentes centrais da expansão da cidadania e redirecionamento do processo produtivo.

\section{Contradições, retrocessos e insurgências}

O Estado capitalista diferencia-se das formas anteriores de poder pela suposição de uma diferenciação entre economia e política, entre os interesses particulares que competem no mercado e o interesse público, assegurado a todos por meio de um aparato estatal legal e coercitivo e pela existência de uma esfera pública distinta em que os conflitos podem ser dirimidos de acordo a regras estabelecidas.

O modo de produção de mercadorias pressupõe que sua realização só possa se dar a partir da circulação, momento que requer a troca entre sujeitos livres e igualados diante da lei, distinguindo, portanto, o indivíduo concreto do cidadão abstrato. Essa separação, na medida em que se institucionalize, permite que o Estado funcione como 'interesse geral do capital' e que a lei cumpra o papel de mediar as contradições entre a igualdade formal e a desigualdade substantiva na produção capitalista. Só assim a exploração da mais valia incorporada à mercadoria se realiza como uma troca espontânea e natural. No entanto, o pleno desenvolvimento de normas legais, impessoais, públicas e administradas constitucionalmente somente tem lugar quando as relações capitalistas estão amadurecidas em uma dada sociedade, o que pressupõe uma correlação de forças na qual o Estado precisa regular a relação capital-trabalho'.

As lutas sociais, contudo, não são exteriores ao Estado, elas o atravessam e se inscrevem em sua materialidade, levando o Estado a organizar a hegemonia ao fixar compromissos entre as classes dominantes e dominadas, e até mesmo impor às primeiras certas perdas materiais ${ }^{2}$ em proveito do interesse geral do capital. Gramsci ${ }^{3}$ nos ensina que o Estado, em suas atividades práticas e teóricas, não somente justifica e mantém a dominação, mas busca obter o consenso ativo dos governados, elevando a massa da população a um determinado nível cultural e moral que corresponde às necessidades de desenvolvimento das forças produtivas.

Ao definir a cidadania como uma hipótese jurídica no Estado capitalista, chamo atenção para as lutas sociais em torno da realização da igualdade formal e sua negação 
pela desigualdade social4 ${ }^{4}$ Ou seja, o desenvolvimento da cidadania, portanto, da democracia de cidadãos, será fruto da correlação de forças e das lutas que se processam a partir dessa situação paradoxal na qual a ordem política se assenta sobre a noção de igualdade em uma sociedade que se funda na desigualdade e exploração de classes.

[...] a conquista da cidadania através da implementação das políticas sociais é sempre o resultado concreto de uma relação de forças das classes em luta pela institucional das relações de força estabelecidas historicamente entre as classes e mediatizadas pelo Estado $[\ldots]^{5(95)}$.

Estudando o desenvolvimento da cidadania na Inglaterra, Marshall 6 reconhece que o princípio igualitário da cidadania permitiu maior integração social preservando a estrutura de desigualdade de classes. No entanto, ele também introduz um princípio de justiça social e a consciência de que a igualdade de direitos não é suficiente, guiando as lutas políticas igualitárias que deram origem aos direitos sociais da cidadania. Polanyi ${ }^{7}$ vê no contramovimento que levou à intervenção estatal na economia e na proteção aos trabalhadores uma reação espontânea às ameaças que o liberalismo representou para a destruição da própria sociedade.

O desenvolvimento dos Estados de BemEstar Social nos países centrais faz parte desse contramovimento, já que representou uma reação ao liberalismo, transformismo que deu lugar à hegemonia da social-democracia, cuja política intervencionista foi capaz, nas condições de um capitalismo regulado, de promover um novo período de expansão e hegemonia. Apesar das diferentes modalidades de proteção social correspondentes a distintas ideologias, correlações de forças e instituições existentes que determinavam a relação entre Estado e Sociedade, a proteção social se expandiu incorporando novos direitos e grupos sociais à cidadania.
Fatores como a urbanização e industrialização estiveram na origem desse processo, gerando uma sociedade de massas, na qual os vínculos de solidariedade orgânica e as relações tradicionais de autoridade foram substituídos por organizações de trabalhadores e partidos que pressionaram pela expansão da igualdade formal para formas substantivas de redistribuição. A expansão do capitalismo industrial e da produção de riquezas, requerendo maior produtividade do trabalho, favoreceram a atenção a essas reivindicações. A confluência de outros fenômenos, como as guerras e o enfrentamento a ideologias do comunismo e do fascismo, também incidiram na mesma direção de reconstrução da hegemonia capitalista em um processo de transformismo, por meio da democracia de massas e da proteção social nos países do capitalismo central. O fortalecimento do Estado com uma administração burocrática racional e impessoal foi imprescindível para que o tratamento diante da lei fosse considerado igualitário.

A expansão da proteção social e o amadurecimento dos Estados de Bem-Estar, todavia, passaram a colocar questões relativas à sua viabilidade e à dinâmica de construção da cidadania. O próprio WF foi visto como tendo transformado os benefícios alcançados com o reconhecimento da classe trabalhadora como um ator coletivo, em consumo individualizado, minando assim as próprias bases que o sustentavam. Por outro lado, a sinergia entre a política econômica Keynesiana e a redistribuição via políticas sociais que estimulava o consumo foi rompida com a crise do capitalismo a partir dos anos 1970, dando lugar à hegemonia neoliberal, pregando a redução do Estado e a lógica competitiva do mercado, a partir dos anos 1980. A proteção trabalhista e social passou a ser vista como uma rigidez que impede a reorganização capitalista ante a crise, ou, evita que o seu custo seja repassado ao trabalho.

Por outro lado, a diversificação e a complexificação da sociedade atual mostram que as lutas pela expansão dos direitos de 
cidadania já não são fruto apenas das lutas da classe operária em suas reivindicações igualitárias, mas de uma polifonia de sujeitos que exigem o reconhecimento da diversidade, em grupos tais como negros, mulheres, Lésbicas, Gays, Bissexuais, Travestis, Transexuais e Transgêneros (LGBT) etc., e políticas distributivas e compensatórias que reduzam as discrepâncias e desvantagens acumuladas em prol da homogeneização burocrática do WS-10.

A cidadania é um status atribuído àqueles que participam de uma comunidade política, portanto intrinsicamente relacionada com a constituição da nação como um espaço político, no interior do qual as diferenças entre a população são superadas por meio de uma discussão pública e o respeito à lei, fundada na noção de bem comum"1. O pertencimento à nação, ou seja, a inclusão na comunidade de cidadãos, requer a internalização de normas partilhadas, implicando a construção do homem universal, o cidadão. Incluindo e integrando alguns, representa, por suposto, a exclusão de outros, os não nacionais, mas também aqueles que são colocados como dependentes ou incapazes, enfim, que não se enquadram na definição do homem universal.

O debate atual sobre a cidadania tem levantado questionamentos sobre a noção de comunidade de cidadãos que está enraizada nos princípios do consenso em relação às normas, mas que ignora o componente insurgente da cidadania que tornou histórica sua expansão, ou seja, a incompletude do corpo político que sempre implica dominação e exclusão. Também se discute o encapsulamento da cidadania à dimensão nacional, na medida em que o poder político e a produção e circulação de mercadorias se desterritorializaram $^{8}$. A esse respeito, Balibar ${ }^{12}$ afirma:

Indeed, the nation, or the national identity, however effective it has been in modern history, is only one of the possible institutional forms of the community of citizens, and it neither encapsulates all of its functions nor comple-

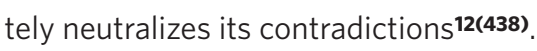

A atual crise do WS, segundo Fraser', pode decorrer de inúmeros fatores, mas um fator crucial é a derrocada da velha ordem de gênero, baseada na existência de famílias nas quais o homem era o provedor do salário que sustentava a todos. Defende que a possiblidade de suplantar o Welfare industrial depende da realização da promessa da igualdade de gênero, que evolui para um modelo de proteção de cuidador universal, o que envolve princípios de antipobreza, antiexploração, igualdade salarial, igualdade de respeito, igualdade de tempo de lazer, antimarginalização e o princípio do antiandrocentrismo.

Alguns autores, com uma perspectiva mais pragmática e funcional, colocam como imperativa a mudança do modelo do WS para o que denominam novo paradigma do investimento social ${ }^{13,14}$, como forma de readequação da proteção social às transformações demográficas, com o aumento do número de idosos e redução da fertilidade, mudanças na composição da força de trabalho, com crescente incorporação de mão de obra feminina, e o aumento do desemprego e da flexibilização das relações de trabalho. Diante de uma sociedade na qual a produção é cada vez mais baseada no conhecimento, essa perspectiva privilegia a educação infantil e treinamento ao longo da vida como forma de melhor aproveitamento do capital humano. Por outro lado, busca atuar na prevenção dos novos riscos:

The social investment perspective also aims at modernising the postwar welfare state so as to better address the new social risks and needs structure of contemporary societies, such as single parenthood, the need to reconcile work and family life, lack of continuous careers, more precarious forms of contracts and possessing low or obsolete skills15(1).

Embora busquem diferenciar-se das críticas neoliberais ao WS, na medida em que o gasto social não é visto como custo, mas como investimento que ativa a economia, 
compartilham com aquela perspectiva a necessidade de desenvolver políticas de ativação e mantêm a crença na eficácia do sistema de mercados. Distinguem-se dos liberais por acreditar que as políticas estatais de qualificação podem gerar alterações no mercado de trabalho, evitando exclusões e aumento da pobreza. As políticas de ativação substituem o Welfare pelo Workfare, seja por meio da redução do benefício, seja por aumento das condicionalidades, levando o beneficiário a se comprometer em melhorar sua qualificação e inserir-se no mercado de trabalho em posições que as políticas públicas lhe oferecem. Ou seja, preparar, mais que reparar.

As principais críticas a essa corrente são relativas à instrumentalização das demandas feministas, com políticas de reconciliação do trabalho; focar na preparação para o futuro e esquecer os pobres atuais; buscar inserir os trabalhadores em qualquer tipo de trabalho; adotar uma perspectiva economicista que trata indivíduos como investimentos e capitais em detrimento da justiça social e da cidadania. Em outros termos, aqueles que não se adequarem à dinâmica produtiva não têm lugar nesse modelo - os dejetos - no qual a solidariedade dá lugar à produtividade como organizador da sociedade.

Além dessas críticas, eu adicionaria a perspectiva individualista em detrimento de uma análise de classes sociais, a aceitação da dinâmica atual do capitalismo como imutável e inexorável (o fim da história), e, finalmente, a inexistência de evidências que provem a relação causal entre aumento da qualificação e transformação da estrutura produtiva e social, com redução da pobreza e da exclusão. O tema da imigração na Europa, onde trabalhadores altamente qualificados exercem atividades desqualificadas e informais, está ausente das considerações dos investidores sociais, bem como as estatísticas de elevado desemprego de jovens universitários e pós-graduados. O fato da cidadania continuar a ser um atributo da nacionalidade, em um mundo globalizado e com elevado nível de circulação das mercadorias, dos capitais e das pessoas, tem acarretado problemas de integração para os imigrantes, excluídos ou colocados em uma condição de subcidadania em países desenvolvidos.

Se a proteção social no WS havia perdido a perspectiva emancipatória da cidadania como conquista de classe para acomodar os beneficiários como consumidores, no investimento social, essa perspectiva de participação em uma comunidade política é substituída pelos incentivos e controles para participação no mercado. A bandeira de 'no welfare without work' e a afirmação de que a política de ativação pavimentou o caminho para a desregulação dos mercados de trabalho ${ }^{13}$ demonstram que a perspectiva do investimento social considera a questão do trabalho como uma atribuição individual, visando ao aumento da empregabilidade, porém, liberando o mercado de responsabilidades pela crescente expulsão dos trabalhadores.

Uma visão instrumental da política social deixa de considerar que toda política social tem uma dimensão metapolítica, na medida em que ela desenha a configuração societária que se pretende alcançar. Assim, a questão fundamental da política social é o enfrentamento da questão social, entendida como aquilo que introduz a perspectiva disruptiva na sociedade, tornando-a incapaz de promover a integração e a coesão social necessárias à legitimação da ordem política.

O trabalho de Wolfgang Streeck ${ }^{16}$ sobre a relação entre capitalismo e democracia busca demonstrar que existe uma incompatibilidade natural entre os dois princípios, ou regimes que guiariam a alocação no capitalismo democrático: um deles atendendo às forças do livre mercado, e o outro baseado nas necessidades sociais e direitos certificados pelas escolhas coletivas das políticas democráticas. Para o autor, a oposição entre mercado e eleitores é inerente, e sua compatibilização só pode se dar em períodos curtos, em que um dos princípios é privilegiado em 
detrimento do outro. Isto acarretará, inevitavelmente, punições, como a perda da maioria por haver negligenciado as demandas dos eleitores ou pela perda de suporte político das forças de mercado que acusam o governo de disfunções econômicas. Conclui-se, portanto, que a crise é o estado natural do capitalismo, sendo os anos de ouro do capitalismo democrático, do pós-guerra até as décadas de 1960 e 1970, uma conjunção rara entre crescimento econômico e distribuição. A partir de então, cresceu a oposição entre o 'povo do mercado' e o 'povo do Estado', estes últimos, os cidadãos que dependem das políticas públicas distributivas ameaçadas com o possível fim do WS. Políticas inflacionárias, aumento do débito privado e público, políticas de austeridade e de liberação financeira foram implementadas diante dos ciclos de crise econômica que se tornaram mais rápidos. Os Estados, que antes eram arrecadadores, transformaram-se em grandes devedores.

Yet democracy is as much at risk as the economy in the current crisis, if not more. Not only has the 'system integration' of contemporary societies - that is, the efficient functioning of their capitalist economies - become precarious, but so has their 'social integration'. With the arrival of a new age of austerity, the capacity of national states to mediate between the rights of citizens and the requirements of capital accumulation has been severely affected $\mathbf{1 6 ( 2 5 ) \text { . }}$

Enfim, a economia globalizada reduz a capacidade política dos Estados nacionais de dar uma resposta alternativa; e a população está cada vez mais desencantada com a representação.

Habermas ${ }^{17}$ concorda com o diagnóstico feito por Streeck ${ }^{\mathbf{1 6}}$ e crê que o maior mérito de sua análise foi ter provado que a imposição de endividamento aos Estados pelos organismos internacionais só beneficia o mercado e aprofunda a crise. No entanto, critica a visão pessimista e, de certa forma, fatalista sobre a desdemocratização apoiando-se em dois argumentos. Por um lado, porque a solução proposta por Streeck ${ }^{\mathbf{1 6}}$ passa pelo fortalecimento dos Estados Nacionais para aumentar a capacidade de regulação dos mercados, $o$ que lhe parece uma opção nostálgica. A internacionalização é um fato que tem beneficiado o mercado, mas deveria ser o caminho para o fortalecimento da cidadania na relação com os Estados. Enquanto a economia está globalmente integrada, a política está fragmentada e deveria buscar formas de maior cooperação internacional para fazer frente a essa defasagem. Por outro lado, afirma:

Más bien, tengo la impresión de que Streeck subvalora el efecto candado de las normas constitucionales válidas no solo desde el punto de vista jurídico sino también del complejo democrático existente de hecho: la persistencia de las instituciones, reglas y prácticas familiarizadas y asentadas en culturas políticas ${ }^{17(38)}$.

Ambos os autores apontam as contradições e desequilíbrios nas relações entre Estado, mercado e cidadania, entendendo seu acirramento na fase atual do capitalismo como um fator de aprofundamento das crises tanto da democracia como do capitalismo. O importante nessa contribuição de Habermas é o resgate da política como um espaço de liberdade, ainda que as contingências econômicas tenham reduzido substancialmente as margens de manobra dos Estados nacionais. No entanto, a saída passa por resgatar e criar formas globalizadas de valorização da política e da cidadania.

Pierson ${ }^{\mathbf{1 8}}$, em seus estudos sobre a reestruturação do WS nas democracias afluentes em tempos de permanente austeridade, parece corroborar a tese de que as instituições e culturas democráticas podem ser um importante antídoto perante as políticas de austeridade. Seus estudos mostram que as mudanças que estão ocorrendo no WS estão sendo desenhadas tanto pelas pressões por austeridade quanto pela duradoura 
popularidade dos sistemas de proteção social. Para ele, todos estão sofrendo pressões para reestruturação, e as mudanças podem até transformar antigos vícios em novas virtudes, eliminando ineficiências e iniquidades. Já as fontes de resistência política às medidas de austeridade são de dois tipos diversos: os incentivos eleitorais em programas que mantêm alta popularidade e a rigidez institucional que resiste aos imperativos de reforma. Juntos, esses fatores criam tremenda resiliência em face das duas décadas de 'crise' do WS ${ }^{18}$. O fato de reconhecer que a adesão ao WS e a resistência institucional são fatores políticos que variam de acordo com os próprios modelos de WS, resistindo ao seu desmantelamento de acordo ao enraizamento do sistema na cultura política e dependendo também da trajetória institucional, não implicam que mudanças e inovações não estejam ocorrendo e nem que as pressões econômicas sejam irrelevantes. Ao contrário, a proteção social sempre dependeu do desenvolvimento econômico e foi por ele condicionada em suas possibilidades e limites.

A recuperação da política no debate sobre desenvolvimento e políticas sociais tem tido como exemplo concreto a situação atual do governo de Portugal com a implementação da política da 'Geringonça', termo usado para designar o atual governo do Partido Socialista que tem como apoiadores o Partido Comunista Português, que nunca aderiu ao eurocomunismo, e o Bloco de Esquerda, que tem suas origens no movimento revolucionário dos anos $1970^{19}$. Esse governo, pressionado por seus aliados de esquerda, levou adiante suas promessas de insubordinação em relação às recomendações dos organismos internacionais de manutenção da política de austeridade: reverteu os cortes anteriores em salários e pensões, suspendeu as privatizações e restaurou os acordos nas negociações coletivas. Em sua análise, Finn encontra as explicações para a sustentação desse governo que se opõe aos ditames das políticas de austeridade na zona do Euro, diferentemente do que aconteceu na Grécia, em razão da ideologia dos partidos de esquerda e sua penetração na sociedade portuguesa. Os resultados positivos em termos de desenvolvimento social e econômico têm angariado suporte interno para o governo, ainda que medidas mais radicais demandadas pela esquerda provavelmente não sejam implementadas. Além disso, alerta para a possibilidade de ameaças externas desestabilizarem o governo diante do crescente deficit público e para a possibilidade de imposição de cortes nos gastos públicos ${ }^{19}$.

Esse caso difere das democracias estudadas por Pierson ${ }^{\mathbf{1 8}}$, em que o enraizamento do WS na cultura política da sociedade e sua trajetória institucional atuam conjuntamente para fortalecer resiliências diante de um contexto de permanente austeridade. Ao contrário, no caso português, a construção das políticas de proteção social foi muito mais recente, e estas começaram a ser desmanteladas pelos governos anteriores que impuseram medidas de austeridade de redução dos benefícios. Só mesmo a história política do país parece ser o fator explicativo para dar conta de tal anomalia, no contexto europeu.

O objetivo de trazer o caso de Portugal foi o de ressaltar a importância da política em uma era na qual os ditames da política de austeridade tornam o discurso econômico do neoliberalismo como cláusula pétrea, e, mesmo que contra factual, continua-se propondo implementar novas medidas que aprofundam a crise econômica e a ruptura da coesão social.

$\mathrm{O}$ aumento do interesse dos eleitores em buscar, por meio do voto, reverter a subordinação das ações estatais aos interesses do mercado, na tentativa de recuperar seu papel de atenção às necessidades dos cidadãos, tem sido denominado como uma onda de retorno do populismo. Streek ${ }^{20}$, em alusão ao contramovimento como reação societal às ameaças do liberalismo, denominou essa tendência como o retorno do reprimido, depois de décadas de globalização e políticas neoliberais, que ameaçam, sob pressão econômica e moral, com a dissolução da sociabilidade e com a incerteza 
dos cidadãos ante os mercados internacionais, cujo controle da crise foi tantas vezes prometido e nunca realizado por essas políticas.

$\mathrm{O}$ aumento da desigualdade e do desemprego além das políticas de contenção de gastos com políticas públicas são cada vez mais intensos, e as promessas de melhorias não se fizeram sentir. Streeck ${ }^{\mathbf{2 0}}$ toma de Gramsci o termo interregnum para designar a fase atual como sendo um período de transição, cuja duração é incerta, entre o velho que está morrendo e o novo que ainda não pode nascer.

O ressurgimento do povo na cena política tem levado a inúmeras considerações sobre a volta do populismo, seja ele de direita ou de esquerda. Como nos ensinou Laclau ${ }^{21}$, as demandas democráticas não atendidas se transformam em demandas populares, constituindo assim um povo, ou seja, uma heterogeneidade que para ser unificada requer a articulação da equivalência das oposições às instituições, possibilitada pela presença de um líder que as unifique. Portanto, inexiste um conteúdo inerente ao populismo, mas condições que possibilitam sua ocorrência, que levam à proliferação de pontos diversos de antagonismos. Para Laclau²1, se fosse para nomear apenas uma condição para emergência do populismo, ele indicaria o capitalismo globalizado.

Rodrik ${ }^{22}$ também crê que a volta do populismo foi causada pela globalização da economia, à qual se associam outros fatores, como mudanças tecnológicas e erosão da proteção ao trabalho, com vantagens sempre direcionadas para o mercado. A fase atual, nomeada de hiperglobalização, aumenta a incidência e intensidade dos conflitos, já que a razão entre os custos políticos/distributivos e os ganhos econômicos é particularmente desfavorável. Particularmente, o diferencial de volatilidade dos capitais em relação ao trabalho permite que os primeiros evitem as barganhas dos trabalhadores e contratem mão de obra mais barata alhures e possam se deslocar, sem serem tão afetados como os trabalhadores, pelos choques em uma economia nacional. Dessa forma, evitam a taxação que permitiria maior redistribuição, e o conflito se acirra na globalização.

No entanto, os sentidos políticos do populismo, que emergem com a agudização dos conflitos, diferenciam-se em populismo de direita e de esquerda: de acordo como os efeitos da globalização, são sentidos na sociedade e articulados pelas suas lideranças em torno de clivagens étnico-culturais pela direita e em torno da renda e classe social pela esquerda. Evidencia-se a preocupação crescente com a falta de legitimidade que acompanhou a globalização, sendo que os reclamos por abertura dos mercados passam a ser substituídos pela necessidade de reequilibrar as órbitas nacional e global e os ganhos que se distribuem de forma tão assimétrica.

No entanto, as consequências políticas da perda de confiança nos sistemas normativos - político e econômico - podem ser desastrosas para toda a sociedade, como aponta Stiglitz ${ }^{23(137)}$ :

The breaking of the social bonds and trust - seen in our politics, in our financial sector, and in the workplace - will, inevitably, have broader societal consequences. Trust and reciprocal goodwill are necessary not only for the functioning of markets but also for every other aspect of societal cooperation. We have explained how the long-term success of any country requires social cohesion - a kind of social contract that binds members of society together. Experiences elsewhere have shown, however, the fragility of social cohesion. When the social contract gets broken, social cohesion quickly erodes.

Ao analisar as manifestações de ocupação de espaços público (como Occupy New York), em nome dos 99\% contra o 1\% mais rico que acumula que acumula a maior fatia da riqueza social, o autor mostra como a concentração de poder econômico aumentou o poder das corporações sobre o Estado, passando a desenhar as políticas públicas em favor de uns poucos, de forma predatória. $\mathrm{O}$ 
Estado de Direito (The Rule of Law), que foi criado para defender os mais fracos em busca de uma sociedade igualitária, passou a ser usado em favor dos poderosos para preservar e aprofundar as desigualdades. Dowbor ${ }^{24}$ explica que o capitalismo hoje prescinde da democracia porque já não há competição entre múltiplas empresas, sendo que só 147 grupos controlam $40 \%$ do sistema corporativo mundial, e há 28 gigantes banqueiros que controlam as próprias empresas produtivas, articulação que começou em 2008.

A contração da esfera política e sua subordinação à dinâmica de acumulação da economia globalizada, representada pela financeirização e pelo poder das corporações, tiveram fortes impactos sobre o WS, restringindo benefícios e acesso às políticas de proteção social, mercantilizando e subordinando à lucratividade os setores sociais, redefinindo a sociabilidade em bases individualistas e competitivas. Aprofundaram-se assim as desigualdades.

Piketti25 angariou prestígio mundial ao mostrar evidências de que as desigualdades se aprofundaram no mundo, recentemente, como consequência de a taxa do rendimento privado do capital ser continuamente mais elevada do que a taxa de crescimento da renda e da produção. A falta de respostas distributivistas dos Estados nacionais, seja em termos de taxação progressiva, seja em investimentos sociais, ameaça os valores de justiça social e a existência das sociedades democráticas. Portanto, a dinâmica da economia da acumulação capitalista é sempre política, tanto porque ameaça a sociedade democrática quanto porque a ação política é a única forma de colocar parâmetros extra econômicos de regulação e distribuição.

Isso nos leva a duas questões imediatamente relacionadas com o lugar do político na conjuntura atual: em que tipo de democracia vivemos? $\mathrm{E}$, será que a cidadania ainda é um conceito capaz de articular a inclusão social?

A resposta de Rancière ${ }^{26}$ é que não vivemos em democracias, nem em totalitarismos biopolíticos, mas em um sistema de dominação de poucos, Estados de Direito oligárquico, limitados pelo duplo reconhecimento da soberania popular e pelas liberdades individuais. Nesse sentido, já não se mantêm as condições originais da democracia enunciadas por Lefort ${ }^{27}$, como um lugar vazio, no qual os governantes se encontram impedidos de se apoderarem dele, um lugar que não podendo ser incorporado às pessoas que o exercem permanecerá em busca do seu fundamento em uma sociedade que acolhe o conflito de opiniões e o debate dos direitos, já que os marcos de referência da certeza se dissolveram ${ }^{27}$. Entretanto, a impossibilidade de o conflito encontrar uma resolução simbólica na esfera política, já que o poder se mostra dentro da sociedade como algo particular, deixa a sociedade despedaçada e insegura. Isso poderia levar a uma sociedade da insegurança total, já que estar protegido não é um estado 'natural'28, mas uma situação construída, garantida pelo Estado social. O atual debilitamento do Estado nacional-social substitui o individualismo positivo, que está na base da cidadania e do seu desenvolvimento em busca de igualdade, por um individualismo negativo, consequência da perda da função integradora do trabalho ${ }^{29}$. Como consequência da precarização do emprego, não apenas aumentam as periferias marginais e o medo às classes perigosas como também ocorre a desestabilização dos estáveis e a fragilização das famílias, ameaçando a coesão social. Castel ${ }^{29}$ chama atenção para as mudanças nas políticas públicas que passam de políticas de integração para políticas de inserção. As políticas de integração sendo aquelas que, buscando uma homogeneização desde o centro, promovem o acesso de todos aos serviços públicos e a redução das desigualdades. Já as políticas de inserção obedecem a uma lógica de discriminação positiva e desenvolvem estratégias específicas para certos grupos e zonas específicas, com o uso de novas tecnologias de intervenção que se distinguem da ajuda social clássica ${ }^{29}$.

A gestão das diferenças é a essência do 
político, e as tentativas de substituição da igualdade pela equidade se mostram insuficientes, já que a equidade apenas pode conduzir a uma busca mais exigente de igualdade, mas não a sua substituição $0^{30}$. Assim, a tentativa que assistimos atualmente de substituir o direito universal à saúde pela cobertura universal fazem parte dessa mesma problemática, na qual se abre mão da igualdade, do direito e da cidadania, com o risco de perpetuar a segmentação social e inviabilizar a solidariedade que é o cimento da coesão social ${ }^{31}$.

A busca da universalidade da cidadania não pressupõe a negação das diferenças sociais, mas, sim, das injustiças que se fundamentam nas diferenças. O universalismo hoje afasta-se da visão idealista e centralizada para propor o reconhecimento da diferença, da multiplicidade de sujeitos, identidades e desejos. O universal e o particular devem buscar novas formas de articulação na democracia contemporânea, assim como a cidadania não é um suporte passivo de direitos, que desconhece as exclusões que estiveram na base de sua construção social, nem uma identidade a mais entre outras. A cidadania deve ser o princípio articulador de diferentes subjetividades que partilham um conjunto de valores ético-políticos, rompendo com a suposição tradicional da cidadania como domínio público dos indivíduos e oposta ao mundo do privado ${ }^{32}$.

No entanto, a questão da identidade não deve ser tomada de um ponto de vista culturalista para pensar uma democracia que comporte as diferenças. Young ${ }^{10}$ afirma que os indivíduos, e não grupos, constroem suas identidades em situações relacionais. Já os grupos sociais podem ser culturais ou estruturais, e estes últimos são os mais importantes nas reivindicações de justiça. E conclui:

Differentiations of gender, race or ability are more likely class than ethnicity, I ague, inasmuch as they concern structural relations of power, resource allocation, and discursive hegemony. Even where the basis of group differentiation more concerns culture than structure, furthermore, claims to cultural recognition usually are means to the end of undermining domination or wrongful deprivation ${ }^{\mathbf{1 0}} \mathbf{8 2 , 8 3 )}$.

A combinação de múltiplas posições estruturais que condicionam as capacidades e privam os indivíduos de liberdades de ação, denominadas por Sartre como serialidade, é aceita por Young ${ }^{10}$, que faz a ressalva de que essas limitações não determinam, no entanto, as identidades individuais. Nosso estudo sobre violência institucional em hospitais públicos bem demonstrou como a discriminação se faz com base em séries de atributos. No entanto, as respostas às discriminações que se materializavam na peregrinação dos pacientes na rede de atenção mostravam que havia diferentes repertórios de respostas dos sujeitos, envolvendo a submissão, a manipulação clientelista, a revolta e a ação política ${ }^{33}$.

Algumas das críticas à abordagem que traz a questão da identidade para o centro da discussão da democracia e da cidadania dizem respeito à dificuldade de construir uma ação coletiva com sujeitos fragmentados em torno de lutas identitárias. Isso, no entanto, não implica que possam haver equivalentes que venham a articular essas diferentes posições em torno de um movimento comum. Outra crítica seria em relação à ameaça à unidade nacional, questão discutida por Kymlinka e Norman ${ }^{34}$ que terminam por concluir que, embora só as reivindicações de autogoverno ponham em risco a unidade nacional, a cidadania diferenciada dificilmente cumpriria uma função integradora.

Poderíamos adicionar que as críticas ao WS relativas à regulação e burocratização, homogeneização e não diferenciação de demandas, exclusão das mulheres etc. não avançam em apontar uma alternativa de economia pós-capitalista compatível com a cidadania diferenciada. Mesmo quando denunciam a convergência entre WS e economia capitalista, terminam deslocando o conflito para a esfera da redistribuição que depende do crescimento da economia privada. 
$\mathrm{O}$ respeito às diferenças encaminha a proposta de democracia deliberativa, em que cada um que seja afetado pela decisão possa participar do debate em uma esfera pública na qual as regras sejam conhecidas e as opiniões sejam argumentadas de forma razoável. Assim, espera-se que sejam superados os problemas decorrentes da formação de uma maioria numérica na democracia representativa, que prescinde do debate de ideias entre os participantes, propiciando o reconhecimento do outro como um igual em termos de respeitabilidade e reciprocidade, que as decisões sejam tomadas em base a princípios de justiça, que a argumentação possa levar à mudança de pontos de vista e que, enfim, esse seja um processo de troca de informações que melhorem a qualidade da própria cidadania ${ }^{35-38}$.

A experiência brasileira com os Conselhos Setoriais antecedeu o próprio desenvolvimento da teoria da democracia deliberativa, mas pode ilustrar tanto suas possibilidades como limitações. Uma limitação da nossa experiência de participação é que se distancia da proposta de democracia deliberativa por não ser um processo aberto a todos os que serão afetados pelas decisões ali tomadas, tendo um sistema de representação embutido na definição dos participantes. Dessa forma, muitas vezes, os interesses corporativos ou até mesmo pessoais podem prevalecer sobre a construção do interesse público.

Uma limitação inerente ao modelo deliberativo decorre da crença que está na base da concepção da esfera pública habermasiana, acerca da existência de um espaço público discursivo sob normas comuns, em que os participantes usem da argumentação razoável para convencimento dos demais, ou para buscar a convergência. Young ${ }^{39}$ defende que a democracia deliberativa proponha um novo modelo da comunicação, que não privilegie o embasamento científico nem a competição, já que esse desenho comunicacional termina por favorecer o discurso masculino e elitista. Ao contrário do discurso formal e de caráter geral, que chega a conclusões em base a inferências e de forma desapaixonada, uma teoria democrática comunicativa deve comportar outras formas de comunicação mais afeitas às mulheres e também às classes populares, que 'puxam o pensamento por meio do desejo', ou seja, a partir de situações emotivas e particulares, incluindo tipos de discursos como a Saudação, a Retórica, e a Narração ${ }^{39}$.

Outra limitação crucial das democracias participativas é relativa ao fato de que as decisões tomadas em processos deliberativos deveriam ser vinculantes, ou compulsoriamente implementadas, o que não acontece com a quase totalidade das instituições participativas no Brasil, à exceção do Orçamento Participativo, cuja metodologia transforma prioridades em valores orçamentários.

A polêmica estabelecida por Fraser ${ }^{40}$ em relação à proposta de Honneth ${ }^{\mathbf{4 1}}$ acerca da adoção de um paradigma moral para balizar os conflitos sociais busca desvendar a falsa antítese entre dois distintos paradigmas de justiça, o redistributivo e o do reconhecimento. Fraser ${ }^{40}$ identifica as características dos dois paradigmas e suas decorrências em termos de enfrentamento das injustiças: por um lado, o paradigma redistributivo tem como foco as injustiças socioeconômicas, tais como a exploração, a marginalização econômica e a privação; por outro, o paradigma do reconhecimento visa as injustiças culturais que levam a padrões de dominação cultural, não reconhecimento e desrespeito.

O paradigma da redistribuição fundamenta-se na teoria Marxista para propor medidas que envolvem a distribuição da riqueza, reorganização da produção e da propriedade, democratização dos investimentos e transformação da estrutura econômica. Já o paradigma do reconhecimento tem suas raízes na teoria social weberiana, na qual o status dos grupos sociais é definido pelas relações de reconhecimento, estima e prestígio que lhe são atribuídos no interior da sociedade. As diferenças, como raça, gênero, etnicidade, são utilizadas como formas de dominação e 
exploração. Portanto, elas devem ser desconstruídas e ou reinterpretadas ${ }^{40}$.

Enquanto para Fraser, mesmo uma categoria como classe social, que tem um fundamento econômico claro, também tem uma dimensão de status, que pode ser englobada no paradigma da redistribuição, para Honneth ${ }^{\mathbf{4 2}}$, as considerações sobre injustiça podem ser unificadas no paradigma do reconhecimento, pois ele estabelece um link entre as causas sociais do sentimento de injustiça e os objetivos normativos dos movimentos emancipatórios.

Este importante diálogo traz muitas contribuições e precisa ser aprofundado, embora tenda a concordar com Boaventura Santos $^{\mathbf{4 3}}$ quando ele afirma que a desigualdade é um fenômeno socioeconômico enquanto a exclusão é, sobretudo, um fenômeno sociocultural fundado em uma normatividade que funciona como discurso de verdade, interditando e rechaçando o outro em base à diferença. A desigualdade permite a exploração, e a exclusão justifica o extermínio. No entanto, a exclusão tem um fundamento econômico ao permitir tanto a exploração quanto a expropriação.

A importância deste debate está em tratar a questão da exclusão como um fenômeno social que tem uma realidade própria, não podendo ser subsumido no debate da cidadania, como sendo algum deficit desse status. O não reconhecimento de moradores de áreas de favelas e periferias urbanas como sujeitos de direito, excluídos, portanto, da condição de cidadania social - ainda que sejam eleitores e a eleição seja a epifania do seu reconhecimento como partícipes -, torna aceitável para a sociedade a violência policial e os assassinatos de jovens negros das favelas. Enquanto os desiguais lutam pela preservação dos direitos adquiridos (Welfare State), os excluídos lutam contra o extermínio, pela sobrevivência e pelo direito a ter direitos (Warfare State). Neste último caso, é o próprio Estado que gera a ilegalidade à qual esta população é circunscrita, e que legitima a coerção $0^{44,45}$. Se o componente da dominação e controle é parte intrínseca do Estado de Bem-Estar Social, a estes se adiciona o componente da violência quando se trata de exclusão social. A dubiedade da sociedade brasileira que, ao mesmo tempo, nega a existência e a realidade das favelas e a destituição dos direitos de seus moradores, relegando-os a uma condição de ilegalidade permanente, enquanto se beneficia dessa mão de obra barata que está disponível na vizinhança ${ }^{46}$, é tanto uma condição de exploração de classe quanto de enraizamento em base a diferenças raciais e culturais que normalizam a exclusão.

O mecanismo da violência como forma de dominação ou como forma de transgressão e insurgência merece ser mais bem estudado na construção da cidadania. Fanon ${ }^{47}$ desenvolveu um trabalho seminal sobre as lutas nacionais anticolonialistas, partindo do pressuposto de que a violência colonial - na qual tudo que é branco é bom e tudo que é negro é ruim - despoja os indivíduos de sua condição humana, impedindo-lhes de se converterem em sujeitos do seu processo social. Fanon ${ }^{47}$ argumenta que só por meio da mesma magnitude de violência o colonizado pode se curar de sua inferioridade e constituir-se, coletivamente, como nação. Contrária a esta posição encontra-se a de Arendt ${ }^{48}$, que distingue poder de violência por sua natureza distinta e por serem antitéticos. Enquanto o poder emerge e tem sua legitimidade na ação coletiva, a violência pode ser justificável, mas nunca será legítima. Trabalhando a questão da democracia e da sociedade civil, Cohen e Arato ${ }^{49}$ concluem que os movimentos sociais são uma dimensão normal da ação política nas sociedades civis modernas. Uma das formas de ação política que eles assumem é a desobediência civil. Por definição, os movimentos sociais são extrainstitucionais; e, embora seja paradoxal a ideia do direito à desobediência civil, os autores consideram que essa forma de ação não viola os princípios da sociedade civil democrática. Argumentam 
que a desobediência civil é uma ação coletiva que pressupõe que os direitos e a democracia estão parcialmente institucionalizados e que os atos de desobediência civil, embora tenham como projeto a utopia democrática, são exemplos de autolimitação do radicalismo ${ }^{49}$. Ademais, exemplificam que muitos atos que foram considerados desobediência civil no passado, como as greves, hoje fazem parte das formas de participação democrática, porque propiciaram a criação e expansão de direitos e da própria democracia.

A proposição de uma democracia radical como estratégia para conquista de uma hegemonia socialista, de Laclau e Mouffe ${ }^{50}$, busca identificar as condições discursivas para a emergência de uma ação coletiva na luta contra as desigualdades e relações de subordinação. Trata-se de buscar as condições nas quais uma relação de subordinação se torna uma relação de opressão, constituindo-se em um lugar de antagonismo ${ }^{50}$. Os autores identificam relações de subordinação como sendo aquelas nas quais um agente submete outro a sua decisão; relações de opressão, como aquelas relações de subordinação que se transformam em lugares de antagonismo, e relações de dominação como o conjunto de relações de subordinação que são consideradas ilegítimas. Entendendo que as formas de resistência às novas formas de subordinação são polissêmicas, propõem sua articulação hegemônica por meio de cadeias de equivalentes. Embora afirmando a necessidade de radicalização da democracia, por meio das relações antagônicas e dos conflitos agônicos, os autores limitam sua proposta para as esquerdas assumirem a defesa de um a democracia radical e plural, conflitos agônicos transacionados dentro das normas democráticas.

Houston $^{51}$ identifica na existência de disjunções nas democracias que não alcançam garantir o conjunto dos direitos de cidadania a todos os seus moradores, em especial para aqueles residentes às margens das grandes metrópoles, a emergência de cidadanias insurgentes. Nessas situações, movimentos de moradores reivindicando melhorias e direitos relativos à sua vida e bem-estar cotidianos politizam o seu dia a dia e se organizam de forma associativa em torno dessas bandeiras. $\mathrm{O}$ autor denominou cidadanias insurgentes todas as formas associativas que encontrou em seu estudo sobre bairros na periferia de São Paulo, de associações de moradores a facções criminosas, que reivindicam direitos denegados, sejam eles direitos à titularidade da moradia, às lutas dos sem-teto, a melhorias nas condições de vida ou nas condições carcerárias. Enquanto a cidadania formal se situa na esfera pública, aqueles que são dela excluídos se organizam a partir da casa, do espaço privado, a partir do qual formulam suas demandas em termos de direitos.

A expansão da cidadania e a consolidação da democracia implicam a construção de um ordenamento legal e institucional, até mesmo em sua constitucionalização $0^{52}$, que assegure o gozo dos direitos e sua exigibilidade. Essas dimensões normativas, legais e institucionais tratam do controle e padronização, portanto da ordem social, seja ela fruto de imposição, de conquistas, de pactos ou deliberações. Sua origem determinará o conteúdo democrático desse ordenamento. No entanto, a cidadania não se trata de um mero status atribuído aos indivíduos como dizia Marshall'b, o que coloca os indivíduos na condição de suporte material dos direitos, mas requer a constituição prévia do sujeito, cuja emergência requer a ruptura com a ordem estabelecida ${ }^{53}$ antes de impor sua presença como ator que transforma esta própria ordem. A ruptura se dá na sua própria constituição, anteriormente denegada na esfera política, o que não quer dizer que sua ação como ator não possa ser reformista ou conservadora.

Termino deixando em aberto as várias formas de desenvolvimento histórico da cidadania para que possamos pensar a forma que melhor se adequaria a atual conjuntura crítica da democracia e da cidadania às palavras de Balibar' ${ }^{12}$ para quem a cidadania 
ultrapassa a democracia e não tem porque restringir-se ao território nacional, sendo que o essencial é a permanente tensão entre os momentos de insurreição e de constituição, no sentido de relações das forças sociais mais estáveis ou menos hegemônicas.

Rights', both individual and collective (and in fact granted to individuals through the efforts of collective movements), are vindicated [as Mary Wollstonecraft (1792) once wrote] and they are sanctioned by 'Law'. But the 'insurrectional' element that accounts for the emancipatory effects of the claim of rights (petitio iuris) can take many forms, which have a different phenomenology in terms of campaigns, party mobilization, temporal condensation or distension, violent or nonviolent relationship of forces, rejection or use of the existing institutions, juridical forms, and so on ${ }^{12(438)}$.

\section{Referências}

1. Jessop B. The Capitalist State. Marxist Theories and Methods. Oxford: Martin Robertson; 1982.

2. Poulantzas N. O Estado, o Poder, o Socialismo. Rio de Janeiro: Graal; 1980.

3. Gramsci A. Maquiavel, a Política e o Estado Moderno. São Paulo: Civilização Brasileira; 1980.

4. Fleury S. Estados sem Cidadãos: Seguridade Social na América Latina. Rio de Janeiro: Fiocruz; 1994.

5. Fleury Teixeira S, organizadora. Reforma Sanitária: Em Busca de uma Teoria. São Paulo: Cortez; 1986.

6. Marshall TH. Cidadania, Classe Social e Status. Rio de Janeiro: Zahar; 1967.

7. Polanyi K. A Grande Transformação: As Origens da Nossa Época. Rio de Janeiro: Campus; 1980.
8. Fleury S. La Expansión de la Ciudadanía in Facultad de Ciencias Políticas y Relaciones Internacionales. Inclusión Social y Nuevas Ciudadanías. Bogotá: Pontificia Universidad Javeriana; 2003. p. 167-194.

9. Fraser N. Gender Equity and the Welfare State: A Postindustrial Thought Experiment. In: Benhabid $\mathrm{S}$, editor. Democracy and Difference. Princeton: Princeton University; 1996. p. 218-24.

10. Young IM. Inclusion and Democracy. New York: Oxford University; 2000.

11. Schnapper D. Community of Citizens: On the Modern Idea of Nationality. London: Transaction Publishers; 1998.

12. Balibar E. The 'impossible' community of the citizens: past and present problems. Environment and Planning D. 2012; 30(3):437-449. 
13. Hemerijck A. Changing Welfare States. Oxford: Oxford University; 2013.

14. Esping-Andersen G. Why we need a new Welfare State. Oxford: Oxford Universit; 2002.

15. Morel N, Palier B, Palme J. Towards a Social Investment Welfare State? Ideas, policies and challenges. Bristol: University of Bristol; 2012.

16. Streeck W. The Crisis of Democratic Capitalism. New Left Review [internet]. 2011 [acesso em 2018 jan 10]; 71:5-29. Disponível em: https://newleftreview.org/II/71/wolfgang-streeck-the-crises-of-democratic-capitalism.

17. Habermas J. ¿Democracia o Capitalismo? Nueva Sociedad [internet]. 2013 [acesso em 2018 jan 10]; 246:32-46. Disponível em: http://nuso.org/articulo/ democracia-o-capitalismo/.

18. Pierson P. Coping with Permanent Austerity: Welfare State Restructuring in Affluent Democracies. In: Pierson P. The New Politics of the Welfare State. Oxford: Oxford University; 2009. p. 410-456.

19. Finn D. Luso- Anomalies. New Left Review [internet]. 2017 [acesso em 2018 jan 10]; 106:5-32. Disponível em: https://newleftreview.org/II/106/daniel-finn-luso-anomalies.

20. Streeck W. The Return of Repressed. New Left Review [internet]. 2017 [acesso em 2018 jan 10]; 104:518. Disponível em: https://newleftreview.org/ II/104/wolfgang-streeck-the-return-of-the-repressed.

21. Laclau E. On Populist Reason. London: Verso; 2005.

22. Rodrik D. Populism and the Economics of Globalization. J Intern Business Policy [internet]. 2018 [acesso em 2018 jan 10]; 1(1-2):12-33. Disponível em: http://www.nber.org/papers/w23559.

23. Stiglitz J. The Price of Inequality: How Today's Divided Society Endangers our Future. New York: Norton \& Company; 2012.
24. Lucena E, Lucena R. TUTAMÈIA entrevista professor Ladislay Dowbor: bando de Chupins Drena a Economia. Tutaméia [internet]. 2018 jul 23 [acesso em 2018 jul 30]. Disponível em: http://tutameia.jor. br/bando-de-chupins-drena-a-economia/.

25. Piketti T. O Capital no Século XXI. Rio de Janeiro: Intrínseca; 2013.

26. Rancière J. El Odio a la Democracia. Buenos Aires: Amorrortu; 2016.

27. Lefort C. Pensando o Político: Ensaios sobre Democracia, Revolução e Liberdade. São Paulo: Paz e Terra; 1991.

28. Castel R. La Inseguridad Social. Buenos Aires: Manantial; 2008.

29. Castel R. As Metamorfoses da Questão Social. 8. ed. Petrópolis: Vozes; 2009.

30. Fitoussi JP, Rosavallon P. La nueva era de las desigualdades. Buenos Aires: Manantial; 2003.

31. Fleury S, Faria M, Durán J, et al. Right to health in Latin America: beyond universalization. Financing Development [internet]. 2013; 249:1-40.

32. Mouffe C. O Regresso do Político. Lisboa: Gradiva; 1996.

33. Fleury S, Bicudo V, Rangel G. Reacciones a la violencia institucional: estrategias de los pacientes frente al contraderecho a la salud en Brasil. Rev Salud Colectiva. 2013 jan-abr; 9(1):11-25.

34. Kymlicka W, Norman W. El retorno del ciudadano: Una revisión de la producción reciente en teoría de la ciudadanía. La Política. 1997 out; 3:5-40.

35. Gutmann A, Thompson D. Why Deliberative Democracy? Princeton: Princeton University Press; 2004.

36. Ester J. Deliberative Democracy. Cambridge: Cambridge University; 1998. 
37. Macedo S. Deliberative Politics: Essays on Democracy and Disagreement. Oxford: Oxford Universit; 1999.

38. Benhabib S. Toward a Deliberative Model of Democratic Legitimacy. In: Benhabid S. Democracy and Difference. Princeton: Princeton University; 1996. p. 67-94.

39. Young IM. Comunicação e o outro: Além da Democracia Deliberativa. In: Souza J. Democracia Hoje: Novos Desafios para a Teoria Democrática contemporânea. Brasília, DF: UNB; 2001. p. 365-386.

40. Fraser N. Social Justice in the Age of Identity Politics: Redistribution, Recognition, and Participation. In: Fraser N, Honneth A. Redistribution or Recognition? A Political-Philosophical Exchange. London: Verso; 2003. p. 7-109.

41. Honneth A. Luta por Reconhecimento: A Gramática moral dos conflitos sociais. São Paulo: Editora 34; 2003.

42. Honneth A. Redistribution as Recognition: A Response to Nancy Fraser in Participation. In: Fraser N, Honneth A. Redistribution or Recognition? A Political-Philosophical Exchange. London: Verso, 2003. p. 110-197.

43. Santos BS. A Construção Multicultural da Igualdade e da Diferença. Rio de Janeiro: VII Congresso Brasileiro de Sociologia; 1995.

44. Fleury S. Do Welfare ao Warfare State. Le Monde Diplomatique Brasil. 2013 fev; 6(67):8-9.
45. Fleury S. A Militarização do Social como Estratégia de Integração: o caso da UPP do Santa Marta. Sociologias. 2012 maio-ago; 14(30):194-223.

46. Fannon F. Os Condenados da Terra. 2. ed. Rio de Janeiro: Civilização Brasileira; 1979.

47. Arendt H. On Violence. Orlando: Harvest Book Harcourt; 1970.

48. Fischer B. A Poverty of Rights: Citizenship and Inequality in Twenty: Century in Rio de Janeiro. California: Stanford University Press; 2008.

49. Cohen JL, Arato A. Civil Society and Political Theory. Massachusetts: MIT Press; 1994.

50. Laclau E, Mouffe C. Hegemony and Socialist Strategy: Towards a Radical Democratic Politics. London: Verso; 1985.

51. Holston J. Insurgent Citizenship: Disjunctions of Democracy and Modernity in Brazil. New Jersey: Princeton University Press; 2008.

52. Fleury S. Brazilian Sanitary Reform: dilemmas between the instituting and the institutionalized. Ciênc Saúde Colet. 2009 maio-jun; 14(3):743-752.

53. Fleury S. Socialismo e Democracia: o lugar do Sujeito. In: Fleury S, Lobato L, organizadoras. Participação, Democracia e Saúde. Rio de Janeiro: Cebes; 2010. p. 24-46.

Recebido em 03/08/2018

Aprovado em 21/08/2018

Conflito de interesses: inexistente

Suporte financeiro: não houve 